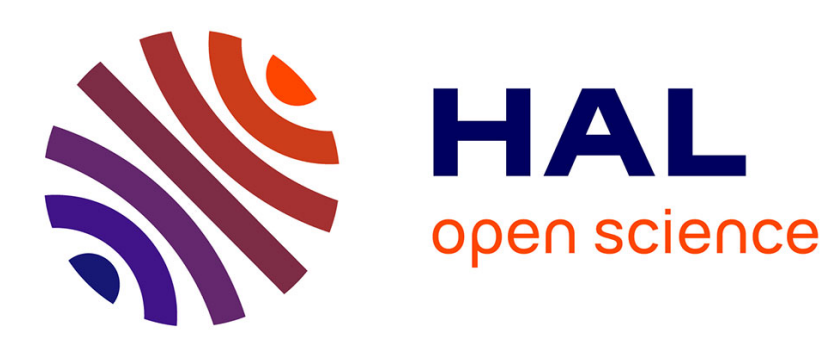

\title{
Energy efficiency optimization of engine by frictional reduction of functional surfaces of cylinder ring-pack system
}

Sabeur Mezghani, Ibrahim Demirci, Mohamed El Mansori, Hassan Zahouani

\section{- To cite this version:}

Sabeur Mezghani, Ibrahim Demirci, Mohamed El Mansori, Hassan Zahouani. Energy efficiency optimization of engine by frictional reduction of functional surfaces of cylinder ring-pack system. Tribology International, 2013, 59, pp.240-247. 10.1016/j.triboint.2012.01.015 . hal-01763341

\section{HAL Id: hal-01763341 \\ https://hal.science/hal-01763341}

Submitted on 10 Apr 2018

HAL is a multi-disciplinary open access archive for the deposit and dissemination of scientific research documents, whether they are published or not. The documents may come from teaching and research institutions in France or abroad, or from public or private research centers.
L'archive ouverte pluridisciplinaire HAL, est destinée au dépôt et à la diffusion de documents scientifiques de niveau recherche, publiés ou non, émanant des établissements d'enseignement et de recherche français ou étrangers, des laboratoires publics ou privés. 


\title{
Energy efficiency optimization of engine by frictional reduction of functional surfaces of cylinder ring-pack system
}

\author{
S. Mezghani, ${ }^{* 1}$ I. Demirci, ${ }^{1}$ M. El Mansori, ${ }^{2}$ H. Zahouani ${ }^{3}$ \\ ${ }^{1}$ Arts et Métiers ParisTech, Rue Saint Dominique, LMPF, 51006 Châlons en Champagne, Cedex, France \\ ${ }^{2}$ Arts et Métiers ParisTech, MécaSurf, 2 cours des Arts et Métiers - F-13617 Aix en Provence, France \\ ${ }^{3}$ Ecole Centrale de Lyon, LTDS, UMR CNRS 5513, 36 avenue Guy de Collongue, 69131 Ecully Cedex, France \\ *Corresponding author: Tel: +33 (0)3 266991 92; Fax: +33 (0)3 266991 76; Email: \\ sabeur.mezghani@chalons.ensam.fr
}

\begin{abstract}
Friction reduction, lower oil consumption, and limitation of greenhouse gases emissions are the chief objectives of the automotive industry in order to improve the environmental efficiency of vehicle engines.

In this paper, a strategy for ring-pack friction reduction through cylinder liner finish optimization based on coupling instrumented honing experiments and numerical prediction of elastohydrodynamic friction is proposed.

The results show that honed surfaces produced by fine abrasion by honing stones yield the optimal elastohydrodynamic friction. They also demonstrate the limitations of ISO 13565 standard roughness parameters in giving a complete description of the functional performances of cylinder surface finishes.
\end{abstract}

Keywords: Honing process, Surface roughness, elastohydrodynamic friction, Cylinder engine.

\section{Nomenclature}

a Hertzian contact radius $(\mathrm{m})$

$\alpha \quad$ Pressure-viscosity coefficient $\left(\mathrm{Gpa}^{-1}\right)$

$\delta \quad$ Elastic deflection of the contacting bodies (m)

$\bar{\delta} \quad$ Dimensionless elastic deflection of the contacting bodies

$\mathrm{D}, \mathrm{d}$ Cylinder diameter before and after the finish honing operation, respectively $(\mathrm{mm})$

$\mathrm{E}_{\mathrm{eq}}, \mathrm{v}_{\mathrm{eq}}$ Equivalent Young's modulus (Pa) and Poisson's coefficient, respectively 
$\mathrm{E}_{\mathrm{i}}, \mathrm{v}_{\mathrm{i}}$ Young's modulus (Pa) and Poisson's coefficient of component $\mathrm{i}$, respectively

$\mathrm{E}_{\mathrm{r}} \quad$ Reduced modulus of elasticity $\frac{2}{E_{r}}=\frac{1-v_{1}^{2}}{E_{1}}+\frac{1-v_{2}^{2}}{E_{2}}$

Esp Specific honing energy $\left(\mathrm{J} / \mathrm{mm}^{3}\right)$

$\mathrm{F}_{\mathrm{N}} \quad$ External applied load $(\mathrm{N})$

h Film thickness (m)

$\mathrm{h}_{0} \quad$ Rigid body displacement (m)

$\mathrm{H} \quad$ Dimensionless film thickness $\left(\mathrm{H}=\mathrm{h} \mathrm{R}_{\mathrm{x}} / \mathrm{a}^{2}\right)$

$\mathrm{H}_{\mathrm{c}} \quad$ Cylinder height (m)

$\mathrm{H}_{0} \quad$ Dimensionless rigid body displacement

$\mathrm{N} \quad$ Dimensionless parameter $N=\frac{\lambda p_{h}^{2} \pi}{12 \mathrm{E}_{\mathrm{r}} \tau_{0}}$

$\eta \quad$ Viscosity (Pa.s)

$\bar{\eta} \quad$ Dimensionless viscosity $\left(=\eta / \eta_{0}\right)$

$\eta_{0} \quad$ Ambient temperature zero-pressure viscosity (Pa.s)

$\overline{\eta_{X}} \overline{\eta_{Y}}$ Effective viscosities in the $\mathrm{X}$ and $\mathrm{Y}$ directions

$\mu \quad$ Friction coefficient

$\mathrm{p} \quad$ Pressure $(\mathrm{Pa})$

$\mathrm{p}_{\mathrm{h}} \quad$ Hertzian pressure $(\mathrm{Pa})$

$\mathrm{P}_{\mathrm{m}} \quad$ Average power absorbed by the honing process $(\mathrm{J})$

$\mathrm{p}_{\mathrm{r}} \quad$ Constant, $\mathrm{p}_{\mathrm{r}}=1.96 .10^{8}(\mathrm{~Pa})$

$\mathrm{P} \quad$ Dimensionless pressure $\left(=\mathrm{p} / \mathrm{p}_{\mathrm{h}}\right)$

$\mathrm{P}^{-} \quad$ Negative part of pressure profile

$\mathrm{Q}_{\mathrm{w}} \quad$ Volumetric removal $\left(\mathrm{mm}^{3}\right)$

$\mathrm{R}_{\mathrm{x}} \quad$ Radius of curvature in $\mathrm{x}$ direction (m)

$\mathrm{Rg}$ height of the liner surface topography at each position (m)

$\rho \quad$ Lubricant density $\left(\mathrm{kg} \cdot \mathrm{m}^{-3}\right)$

$\bar{\rho} \quad$ Dimensionless lubricant density $\left(=\rho / \rho_{0}\right)$

$\rho_{0} \quad$ Lubricant's density under ambient condition $\left(\mathrm{kg} \cdot \mathrm{m}^{-3}\right)$

$\mathrm{S} \quad$ Slide to roll ratio: $\mathrm{S}=2\left(\mathrm{u}_{1}-\mathrm{u}_{2}\right) /\left(\mathrm{u}_{1}+\mathrm{u}_{2}\right)$

$\sigma_{\mathrm{n}} \quad$ Normal stress component

$t_{\text {honing }}$ Effective honing time (s)

$\overline{\tau_{m}} \quad$ Dimensionless mean shear stress

$\tau_{0} \quad$ Eyring stress $(\mathrm{Pa})$ 
U Elastic displacement vector (m)

$\mathrm{u}_{\mathrm{i}} \quad$ Surface velocity of body I in $\mathrm{X}$-direction $\left(\mathrm{m} . \mathrm{s}^{-1}\right)$

$\mathrm{u}_{\mathrm{m}} \quad$ Mean entrainment velocity $\left(\mathrm{m} . \mathrm{s}^{-1}\right)$

$\mathrm{X}, \mathrm{y}, \mathrm{z} \quad$ Space coordinates $(\mathrm{m})$

$\mathrm{X}, \mathrm{Y} \quad$ Dimensionless space coordinates (=x/a, y/a)

w Value of Z-component of the displacement vector (m)

$\zeta \quad$ Penalty term parameter

$z_{r} \quad$ Pressure viscosity index (Roelands), $z_{r}=p_{r} \alpha /\left(\ln \left(\eta_{0}\right)+9.67\right)$

\section{Introduction}

The surface features of a cylinder liner engine are the fingerprint of the successive processes the surface has undergone, and they influence the functional performance of the combustible engine [1-5]. Therefore, surfaces and their measurement provide a link between the manufacture of cylinder bores and their functional performances [6]. Hence, the quantitative characterization of surface texture can be applied to production process control and design for functionality [7]. The optimum surface texture of an engine cylinder liner should ensure quick running-in, minimum friction during sliding, low oil consumption, and good motor engine operating parameters in terms of effective power and unitary fuel consumption. Increasingly stringent engine emissions standards and power requirements are driving an evolution in cylinder liner surface finish [8]. Unfortunately, the full effect of different cylinder liner finishes on ring-pack performance is not well understood [7].

In mass production of internal combustion engine cylinder liners, the final surface finish on a cylinder bore is created by an interrupted multistage abrasive finishing process, known as the plateau-honing process. In honing, abrasive stones are loaded against the bore and simultaneously rotated and oscillated. Characteristically, the resulting texture consists of a flat smooth surface with two or more bands of parallel deep valleys with stochastic angular position. Figure 1 shows a typical plateau-honed surface texture from an engine cylinder.

To guarantee efficient production at industrial level of a cylinder liner of specific shape with acceptable dimensional accuracy and surface quality, three honing stages are usually required: rough honing, finish honing, and plateau honing. The surface texture is presumably provided by the "finish honing" [9, 10]. Thus careful control of this operation is central to the production of the structured surface so that the cylinder liner will fulfil its mechanical contact 
functionalities in piston ring/cylinder liner assemblies (i.e. running-in performance, wear resistance, load-carrying capacity, oil consumption, etc.) $[9,11]$.

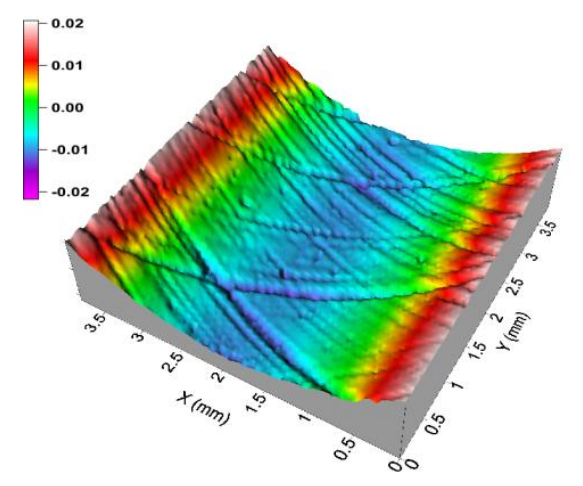

Figure 1 Typical plateau-honed surface texture

Nevertheless, successful application of honing has long been dependent on the empirical optimization of setup and operation variables such as cutting speed, honing expansion pressure, and grit size. For this reason, in the development of strategies for piston ring-pack friction reduction through cylinder liner finish optimization it is necessary to be able to distinguish the effect of each process variable on the roughness of these honed surfaces [7].

In this work, strategies for piston ring-pack friction reduction through cylinder liner finish optimization were analyzed with the goal of improving the efficiency of selection of the honing process variable. The fundamental aim was to find a relation between the honing operating variables and the hydrodynamic friction at the piston rings/cylinder interface. An additional aim was to determine how the cylinder surface micro-geometry of plateau-honed cylinders affects the predicted friction. Thus, an experimental test rig consisting of an industrial honing machine instrumented with sensors to measure spindle power, expansion pressure, and honing head displacement was developed. Honing experiments were carried out using honing stones with varying sizes of abrasive grits and varying expansion speeds, that is, the indentation pulse of the honing stone's surface against the liner wall. Furthermore, a numerical model of lubricated elastohydrodynamic contact was developed to predict the friction performances and lubricant flow of the various liner surface finishes. It uses the real topography of the liner surface as input. In fact previous studies have found that the detailed nature of the surface finish plays an important role in ring friction and oil film thickness predictions [12]. An appreciation of the limitations of the surface roughness parameters 
commonly used in automotive industries in providing a link between the honing process and the generated surface performance in the hydrodynamic regime is presented.

\section{Experimental procedure}

In this work, honing experiments were carried out on a vertical honing machine with an expansible tool (NAGEL no. 28-8470) (Figure 2). The workpiece consists of four cylinder liners of a lamellar gray cast iron engine crankcase.

The steps involved in the fabrication of the cylinder liners before the finish-honing operation are boring and rough honing, respectively (Table 1). Each cylinder has a diameter equal to $75.937 \mathrm{~mm}$ and a height of $141 \mathrm{~mm}$. Instrumented finish honing tests were performed with a Vitrified Bonded Silicon Carbide (VBSC) stick, where the average grit size was varied from $30 \mu \mathrm{m}$ to $180 \mu \mathrm{m}$. It is in fact an IAS65/100I8S conventional stone with an initial mixture of 65 vol.\% aluminum oxide and 35 vol.\% green silicon carbide, which corresponds to a soft grade, a large openness of the structure, and a vitrified bond resulting from a special treatment by impregnation with sulfur. Another interesting variation in the feed system is the expansion mechanism in the honing head, where three expansion velocities " $\mathrm{V}_{\mathrm{e}}$ " $(1.5 \mu \mathrm{m} / \mathrm{s}$, $4 \mu \mathrm{m} / \mathrm{s}$ and $8 \mu \mathrm{m} / \mathrm{s}$ ) were considered. All the other working variables were kept constant (Table 1). Note that the rough and finish honing operations use a mechanical expansion system and the plateau honing uses a hydraulic system.
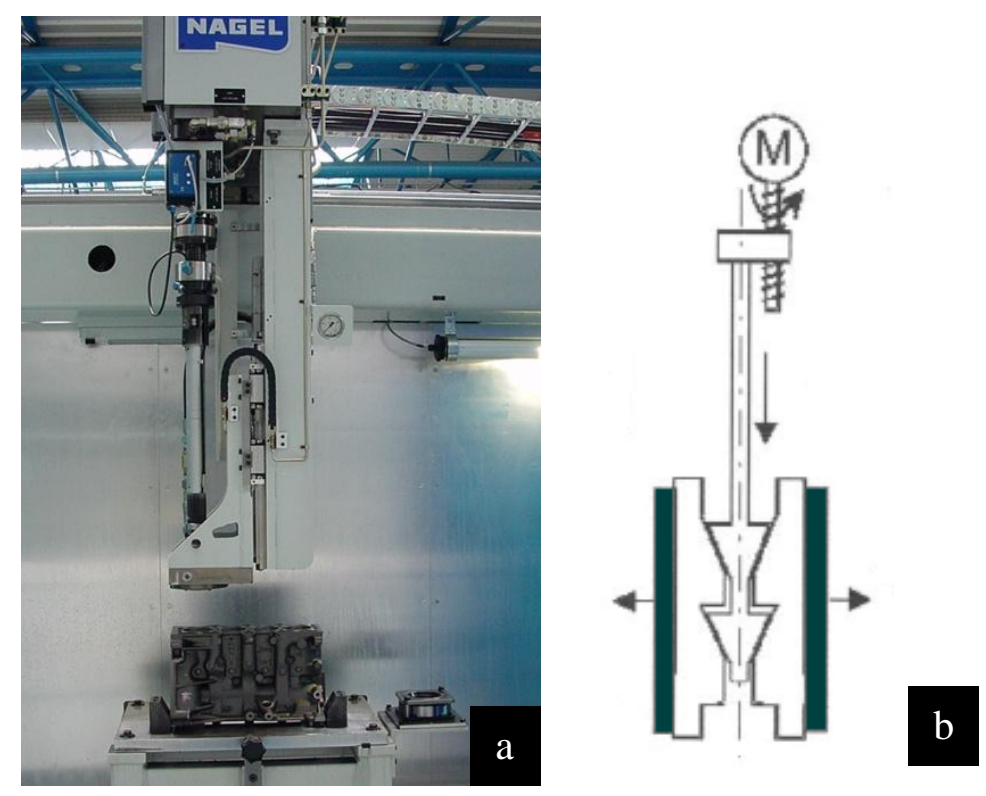

Figure 2 (a) Vertical honing machine with expansible tool; (b) Schematic representation of the honing head in continuous balanced movement. 
For each combination of grit size and expansion velocity, tests were repeated five times. Thus, the sensitivity of the produced surface finish to its generation process was considered.

Negative surface replicas made of a silicon rubber material (Struers, Repliset F5) were used to assess the texture of honed surfaces after the plateau-honing stage at the mid-height of the cylinder bore specimen. Topographical features of replica surfaces were measured in three locations by a three-dimensional white light interferometer, WYKO 3300 NT (WLI). The surface was sampled at $640 \times 480$ points with the same step scale of $1.94 \mu \mathrm{m}$ in the $\mathrm{x}$ and $\mathrm{y}$ directions. Form component is removed from acquired 3D data using least square method based on cubic Spline function.

We can assume that the initial roughness of the cylinder bore has no influence on the obtained surface texture in this study. It affects only the honing cycle and the stone life, that is, the wear of the abrasive grits. In fact, the thickness of the removed material after finish honing $(32.17 \pm 2.21 \mu \mathrm{m})$ is greater than the total height of the original surface, which was about $24.56 \pm 6.75 \mu \mathrm{m}$. This means that the finish honing operation completely penetrates the original surface topography and generates a new surface texture.

Table 1 Honing working conditions

\begin{tabular}{|l|l|l|l|}
\hline Honing process variables & Rough honing & Finish honing & Plateau honing \\
\hline $\mathrm{V}_{\mathrm{a}}:$ Axial speed $(\mathrm{m} / \mathrm{min})$ & 28 & 28 & 28 \\
\hline $\mathrm{V}_{\mathrm{r}: \text { Rotation speed }(\mathrm{rpm})}$ & 230 & 230 & 230 \\
\hline Honing time $(\mathrm{sec})$ & 20 & 15 & 2 \\
\hline Expansion type & Mechanical & Mechanical & Hydraulic \\
\hline $\mathrm{V}_{\mathrm{e}}:$ Expansion velocity $(\mu \mathrm{m} / \mathrm{s})$ & 5 & $1.5,4$, and 8 & \\
\hline Number of stones & 6 & 6 & 6 \\
\hline Abrasive grit type & Diamond & Silicon carbide & Silicon carbide \\
\hline Grain size $(\mu \mathrm{m})$ & 125 & $30-180$ & 30 \\
\hline Bond type & Metal & Vitrified & Vitrified \\
\hline $\begin{array}{l}\text { Abrasive stone dimensions } \\
(\text { mm } \times \text { mm } \times \text { mm })\end{array}$ & $2 \times 5 \times 70$ & $6 \times 6 \times 70$ & $6 \times 6 \times 70$ \\
\hline
\end{tabular}

\section{Numerical model for hydrodynamic friction simulation in piston ring- pack system}

A numerical model was developed to estimate friction at the ring-liner-piston contact. It takes into account the real topography of the cylinder liner. The scope of this model is to predict qualitatively the friction coefficient obtained to optimize the performances when the groove characteristics of cylinder liner surfaces are variables. 


\subsection{Geometry definition}

An incompressible viscous fluid occupying, at a given moment, a field limited by a smooth plane surface $\mathrm{P}$ and by a rough surface $\mathrm{R}$ is considered. This field is represented on figure 3 (we did not represent the profile in the $\mathrm{x} 2$ direction). It extends from 0 to 11,0 to 12 and $\mathrm{h}$ ( $\mathrm{x} 1$, $\mathrm{x} 2$ ) respectively according to $\mathrm{x} 1, \mathrm{x} 2$ and $\mathrm{x} 3 \mathrm{~h}(\mathrm{x} 1, \mathrm{x} 2)$ represents the fluid thickness. The smooth body is animated by a movement at the constant velocity " $u 1$ " along Ox1 axis whereas rough surface is static.

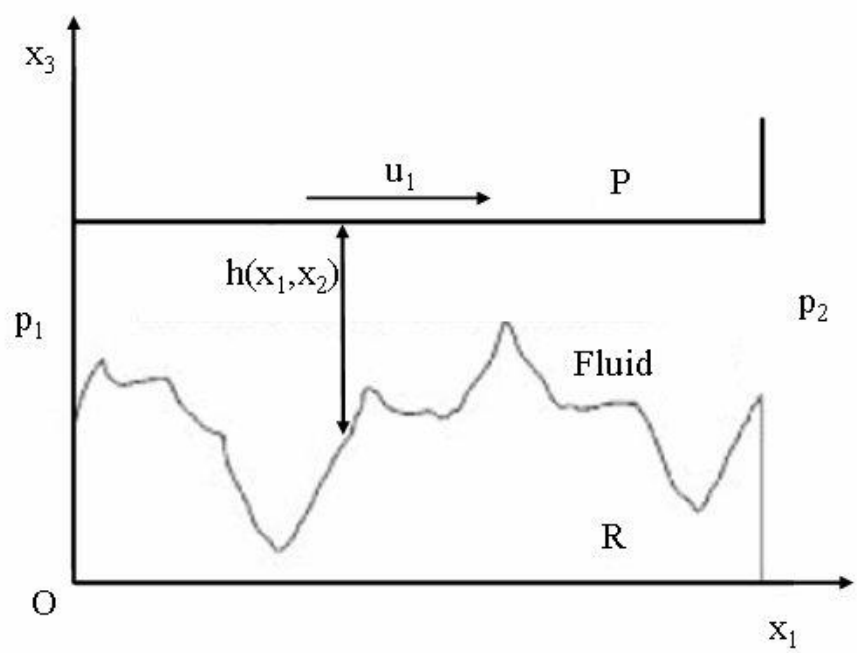

Figure 3 The separation field between a smooth surface and a rough one

\subsection{EHL Equations}

To estimate the pressure distribution, film thickness, and friction coefficient, a full system approach for elastohydrodynamic lubrication (EHL) was developed. The Reynolds equations have been written in dimensionless form using the Hertzian dry contact parameters and the lubricant properties at ambient temperature. To account for the effects of non-Newtonian lubricant behaviour effectives viscosities are introduced.

$$
\frac{\partial}{\partial X}\left(\frac{\bar{\rho} H^{3}}{\lambda \overline{\eta_{X}}} \frac{\partial P}{\partial X}\right)+\frac{\partial}{\partial Y}\left(\frac{\bar{\rho} H^{3}}{\lambda \overline{\eta_{Y}}} \frac{\partial P}{\partial Y}\right)=\frac{\partial \bar{\rho} H}{\partial X}
$$

With the boundary condition $\mathrm{P}=0$ and the cavitation condition (or free boundary condition) $\mathrm{P} \geq 0$ are used everywhere Special treatment is used for cavitation condition as explained below. In this equation, $\lambda$ is equal to $\frac{12 \eta_{0} \rho_{0} u_{m}}{a^{3} p_{h}} . \overline{\eta_{X}}$ and $\overline{\eta_{Y}}$ are the effective viscosities in the $\mathrm{X}$ and $\mathrm{Y}$ directions, respectively. For point contact, it is not possible to derive these effective 
viscosities analytically. The perturbational approach described by Ehret et al. [13] is used. This analysis is based on the assumption that the shear stresses are only partially coupled and that the mean shear stress is negligible in the y direction $[13,14]$.

In our model, the Eyring model is used. The perturbational approach leads to the following dimensionless effective viscosities:

$$
\overline{\eta_{X}}=\frac{\bar{\eta}}{\cosh \left(\overline{\tau_{m}}\right)} \text { and } \overline{\eta_{Y}}=\frac{\bar{\eta} \overline{\tau_{m}}}{\sinh \left(\overline{\tau_{m}}\right)}
$$

where the dimensionless mean shear stress is written as:

$$
\sinh \left(\overline{\tau_{m}}\right)=N \frac{\bar{\eta} S}{\mathrm{H}}
$$

where $\mathrm{S}$ is the slide to roll ratio $\left(2\left(\mathrm{u}_{1}-\mathrm{u}_{2}\right) /\left(\mathrm{u}_{1}+\mathrm{u}_{2}\right)\right)$ and $\mathrm{N}$ is given by :

$$
N=\frac{\lambda p_{h}^{2} \pi}{12 \mathrm{E}_{\mathrm{r}} \tau_{0}}
$$

The constant parameters of Equation (5) are given in the nomenclature.

The lubricant's viscosity and density are considered to depend on the pressure according to the Dowson and Higginson relation [15] (Eq. 6) and Roelands equation [16] (Eq. 7):

$$
\bar{\rho}(P)=\left[1+\frac{0.6 \times 10^{-9} P \cdot p_{h}}{1+1.7 \times 10^{-9} P \cdot p_{h}}\right]
$$

where $\rho_{0}$ is the density at ambient pressure.

$$
\bar{\eta}(P)=\exp \left(\left(\ln \left(\eta_{0}\right)+9.67\right)\left(-1+\left(1+\frac{P \cdot p_{h}}{p_{r}}\right)^{Z_{r}}\right)\right)
$$

where $\eta_{0}$ is the viscosity at ambient pressure, $\mathrm{p}_{\mathrm{r}}$ is a constant equal to $1.96 \times 10^{8}$, and $\mathrm{z}_{\mathrm{r}}$ is the pressure viscosity index $\left(\mathrm{z}_{\mathrm{r}}=0.65\right)$.

The film thickness equation is given in dimensionless form by the following equation:

$$
H(X, Y)=H_{0}+\frac{X^{2}}{2}+\frac{Y^{2}}{2}+\bar{\delta}(X, Y)-\overline{R g}(X, Y)
$$

$\overline{R_{g}}$ is the height of the liner surface topography at each position $(\mathrm{X}, \mathrm{Y}) . \mathrm{H}_{0}$ is a constant determined by the force balance condition:

$$
\iint_{\Omega_{\mathrm{C}}} P(X, Y) d X d Y=\frac{2 \pi}{3}
$$

The normal elastic displacement $\bar{\delta}(X, Y)$ of contacting bodies is obtained by solving the linear elasticity equations in three-dimensional geometry with appropriate boundary conditions $[17,18]$. The geometry $(\Omega)$ used (figure 4 ) is large enough compared to contact 
size $\left(\Omega_{\mathrm{c}}\right)$ to be considered as semi-infinite structures. The linear elastic equations consist of finding the displacement vector $U$ in the computational domain $\Omega$ with the following boundary conditions:

$$
\begin{cases}U=0 & \text { at the bottom boundary } \\ \sigma_{n}=-P & \text { at the contact area boundary } \Omega_{\mathrm{C}} \\ \sigma_{n}=0 & \text { elsewhere }\end{cases}
$$

In order to simplify the model, the equivalent problem defined by [18] is used to replace the elastic deformation computation for both contacting bodies. One of the bodies is assumed to be rigid while the other accommodates the total elastic deformation. The following material properties of the bodies are used in order to have $\bar{\delta}(X, Y)=|w(X, Y)|$ (w is the dimensionless absolute value of the Z-component of the displacement vector):

$$
\begin{gathered}
E_{e q}=\frac{E_{1}^{2} E_{2}\left(1+v_{2}\right)^{2}+E_{2}^{2} E_{1}\left(1+v_{1}\right)^{2}}{\left[E_{1}\left(1+v_{2}\right)+E_{2}\left(1+v_{1}\right)\right]^{2}} \frac{a}{R_{x} p_{h}} \\
v_{e q}=\frac{E_{1} v_{2}\left(1+v_{2}\right)+E_{2} v_{1}\left(1+v_{1}\right)}{E_{1}\left(1+v_{2}\right)+E_{2}\left(1+v_{1}\right)}
\end{gathered}
$$

where $E_{i}$ and $v_{i}$ are the Young's modulus and Poisson's coefficient, respectively, of the material for contacting bodies $(i=1,2)$.

Finally, the friction coefficient is evaluated by the following formula:

$$
\mu=\frac{\tau_{0} \iint_{\Omega_{c}} \overline{\tau_{m}}(X, Y) d X d Y}{p_{h} \iint_{\Omega_{c}} P(X, Y) d X d Y}
$$

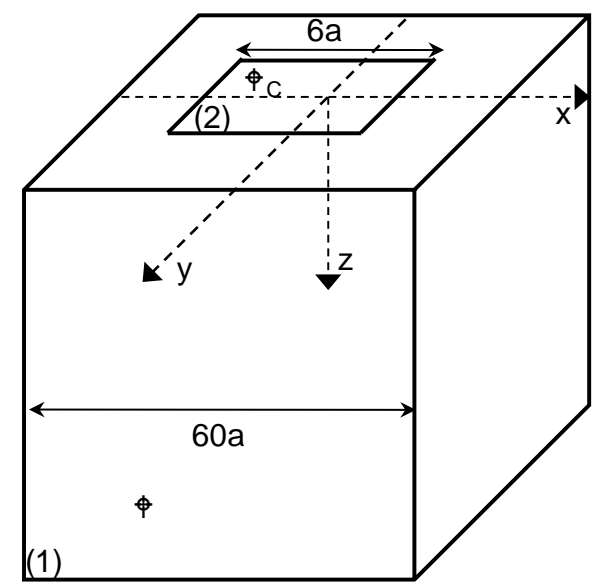

Figure 4 Scheme of geometric model for computations of the elastic deformation (1) and of the Reynolds equation (2).

\subsection{Cavitation problem}


Usually, negative pressure appears in the resolution of the Reynolds equation. Physically, these negative pressures are not relevant. In such cases, the fluid will evaporate and the pressure is limited by the vapor pressure of the fluid. This process is the cavitation. This problem is usually solved by setting the negative pressure to zero. This ensures that there will be zero pressure and gradient pressure on the free boundary. In the full system approach, this solution is not possible and the penalty method is used as an alternative, as explained in [18]. This method was introduced in EHL by Wu [19]. An additional penalty term was introduced in the Reynolds equation:

$$
\frac{\partial}{\partial X}\left(\frac{\bar{\rho} H^{3}}{\lambda \overline{\eta_{x}}} \frac{\partial P}{\partial X}\right)+\frac{\partial}{\partial Y}\left(\frac{\bar{\rho} H^{3}}{\lambda \overline{\eta_{y}}} \frac{\partial P}{\partial Y}\right)=-\varsigma P^{-}+\frac{\partial \bar{\rho} H}{\partial X}
$$

where $\zeta$ is a large positive number and $P^{-}=\min (P, 0)$ is the negative part of the pressure distribution. This penalty term constrains the system to $\mathrm{P} \geq 0$ and forces the negative pressure to zero.

\subsection{Numerical procedure}

The Reynolds equation, linear elastic equations, and load balance equation are simultaneously solved using a Newton-Raphson resolution procedure. The dimensionless viscosity $\bar{\mu}$, density $\bar{\rho}$, and film thickness $\mathrm{H}$ in the Reynolds equation are replaced by the expression given above. Except for the load balance equation, a standard Galerkin formulation is used. For the load balance equation, an ordinary integral equation is added directly with the introduction of an unknown $\mathrm{H}_{0}$. Unstructured variable tetrahedral meshing is used for both Reynolds and linear elastic equations. A total number of 100000 degrees of freedom are used in the simulation. An iterative process is repeated until the maximum relative difference between two consecutive iterations reaches $10^{-6}$. Table 2 summarizes the fluid properties and contact parameters used in our simulation.

Table 2 Parameters for our simulation used with rough surfaces

\begin{tabular}{|llll|}
\hline Parameter & Value & Parameter & Value \\
\hline \hline $\mathrm{F}_{\mathrm{N}}(\mathrm{N})$ & 500 & $\alpha\left(\mathrm{GPa}^{-1}\right)$ & 22.00 \\
$\mathrm{u}_{\mathrm{m}}\left(\mathrm{m} . \mathrm{s}^{-1}\right)$ & 10.0 & $\mathrm{R}_{\mathrm{x}}(\mathrm{m})$ & 0.04 \\
$\eta_{0}(\mathrm{~Pa} . \mathrm{s})$ & 0.04 & $\mathrm{E}_{\mathrm{i}}(\mathrm{GPa})$ & 210 \\
$\mathrm{v}_{\mathrm{i}}$ & 0.3 & $\tau_{0}(\mathrm{MPa})$ & 0.5 \\
\hline
\end{tabular}

Table 3 gives dimensionless central and minimum oil film thickness for the following dimensionless Moes and Venner parameters $\mathrm{M}=200$ and $\mathrm{L}=10$. 
The difference between our model and Venner and Lubrecht work [20] is less than $1 \%$. This test confirms the validity of the model presented in this paper. Figure 5 show an example of a pressure distribution and film thickness profiles along the central line in the $\mathrm{X}$ direction for rough surface like one presented in Figure 6.

Table 3 Comparison of the current model with the Venner \& Lubrecht model [20]

\begin{tabular}{|c|c|c|}
\hline & Venner and Lubrecht [20] & Curent model \\
\hline Central oil film thickness Hc & 0.08093 & 0.08150 \\
\hline Minimum oil film thickness Hm & 0.03876 & 0.03905 \\
\hline
\end{tabular}

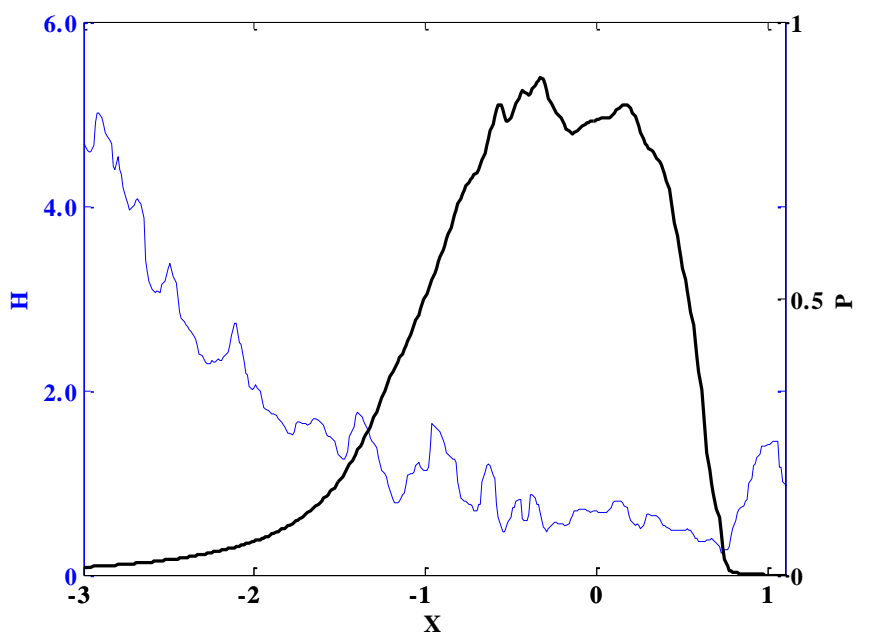

Figure 5 Pressure $(\mathrm{P})$ and film thickness $(\mathrm{H})$ profiles along the central line in the $\mathrm{X}$ direction.

\section{Results and discussion}

The numerical model presented in Section 3 was used to predict friction in the ring-linerpiston contact and to analyze possible friction reduction strategies in the piston ring-pack. Table 4 regroups all the experimental and numerical results. As a result of simulation of the cylinder ring-pack contact, only the average friction coefficients were compared.

Cylinder liner surface roughness distribution can differ between surfaces with the same root mean square roughness. This difference can have a significant effect on the performance and behavior of the surface within the piston ring-pack system.

\subsection{Influence of abrasive grit size and expansion velocity on the impregnated surface} texture and its friction performance within the piston ring-pack system 
The surface finish created by the honing process is controlled by the size and dispersion of abrasive particles adhering to the surface of the honing sticks. Figure 6 shows the effect of varying the grit size of abrasive honing stones used in the finish honing stage on the threedimensional topographical features of the produced surface. As shown in Figure 6, coarse abrasive grits yield deeper and larger lubrication valleys and consequently rougher surfaces.

Table 4 Honing process variables, roughness parameters of honed surfaces and theirs predicted coefficient of friction

\begin{tabular}{|c|c|c|c|c|c|}
\hline Ve & Grit size & Rpk & $\mathbf{R k}$ & Rvk & $\mu(\%)$ \\
\hline 1.5 & 180 & 0.663 & 1.859 & 1.960 & 2.495 \\
\hline 1.5 & 145 & 0.777 & 1.798 & 2.429 & 2.466 \\
\hline 1.5 & 110 & 0.679 & 1.813 & 2.025 & 2.474 \\
\hline 1.5 & 90 & 0.564 & 1.954 & 1.825 & 2.459 \\
\hline 1.5 & 80 & 0.566 & 1.628 & 1.678 & 2.426 \\
\hline 1.5 & 50 & 0.253 & 0.625 & 0.598 & 2.441 \\
\hline 1.5 & 40 & 0.217 & 0.659 & 0.426 & 2.446 \\
\hline 4 & 180 & 1.091 & 2.680 & 3.650 & 2.543 \\
\hline 4 & 145 & 1.091 & 2.418 & 3.455 & 2.468 \\
\hline 4 & 110 & 0.979 & 2.521 & 2.969 & 2.465 \\
\hline 4 & 90 & 0.913 & 2.045 & 2.720 & 2.447 \\
\hline 4 & 80 & 0.838 & 2.016 & 2.800 & 2.434 \\
\hline 4 & 50 & 0.353 & 0.622 & 0.748 & 2.459 \\
\hline 4 & 40 & 0.287 & 0.931 & 0.530 & 2.450 \\
\hline 8 & 180 & 1.292 & 3.403 & 4.276 & 2.462 \\
\hline 8 & 145 & 1.308 & 2.922 & 4.057 & 2.487 \\
\hline 8 & 110 & 1.135 & 2.828 & 3.469 & 2.462 \\
\hline 8 & 90 & 1.096 & 2.534 & 3.213 & 2.488 \\
\hline 8 & 50 & 0.521 & 1.007 & 1.263 & 2.461 \\
\hline 8 & 40 & 0.359 & 0.510 & 0.644 & 2.442 \\
\hline
\end{tabular}

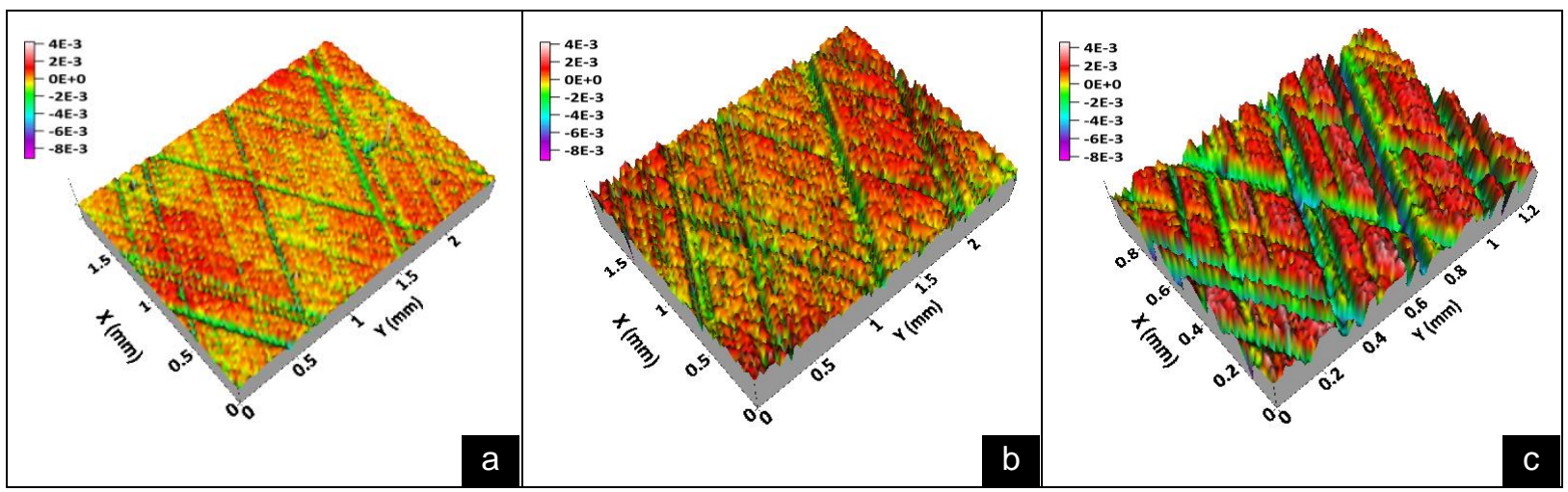

Figure 6 Three-dimensional topographies of plateau-honed surfaces produced using different abrasive grit sizes in the finish honing stage: (a) $40 \mu \mathrm{m}$, (b) $110 \mu \mathrm{m}$, and (c) $180 \mu \mathrm{m}$. (Process 
working variables: $\mathrm{V}_{\mathrm{e}}$ in finish honing stage $=4 \mu \mathrm{m} / \mathrm{s}$; all others parameters are kept constant and are given in Table 1.)

As a result of these honing experiments carried out with various sizes of abrasive grits, Figure 7 presents predicted values of the coefficient of friction and mean oil film thickness as a function of abrasive grit size of honing stone used at the finish honing stage.

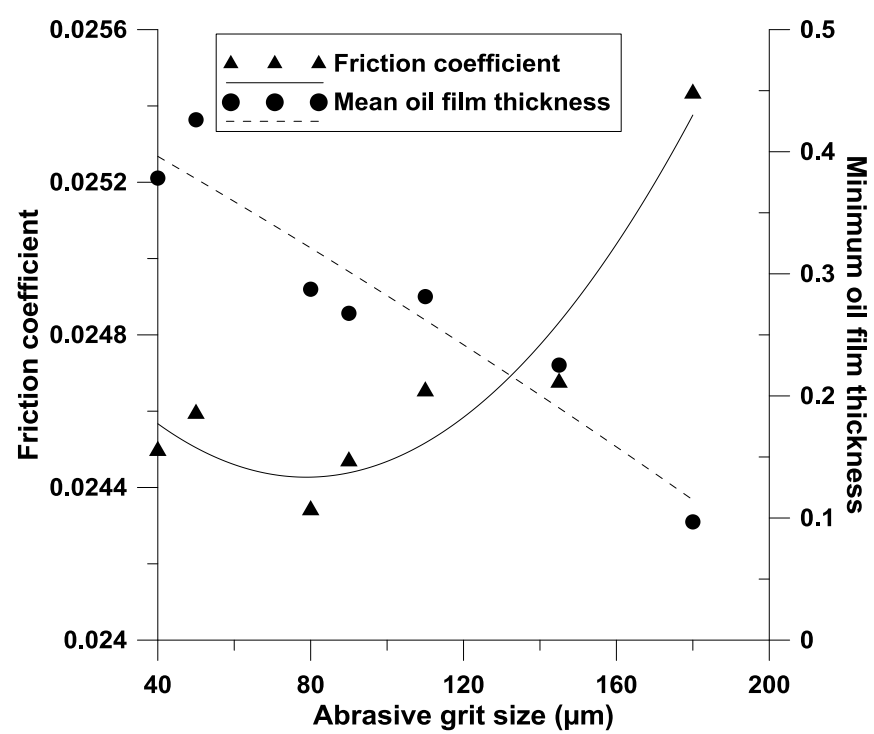

Figure 7 Evolution of friction coefficient of the cylinder ring-pack as a function of the abrasive grit size in the honing finish stage.

It demonstrates clearly that the surface texture achieved with finer abrasive grits yields a lower hydrodynamic friction coefficient in a cylinder ring-pack system than that obtained by coarse abrasive grits. Since the generated honed surfaces have the same honing cross-hatch angle, the differences in predicted hydrodynamic friction observed between these different finishes are mainly a result of surface peak and valley characteristics. Hence, the increase in valleys volume may increase the oil supply through the valleys of the surface, yielding a decrease in the oil film thickness, which will in turn induce an increase in hydrodynamic friction.

A reduction of the expansion speed operating condition leads to lower valley depth on the surface texture impregnated during coarse honing as observed in Figure 8. This figure also shows that the expansion velocity has no effect on the spatial morphology of the generated surface texture and hence the roughness scale, as demonstrated by multiscale surface analysis in [8]. 


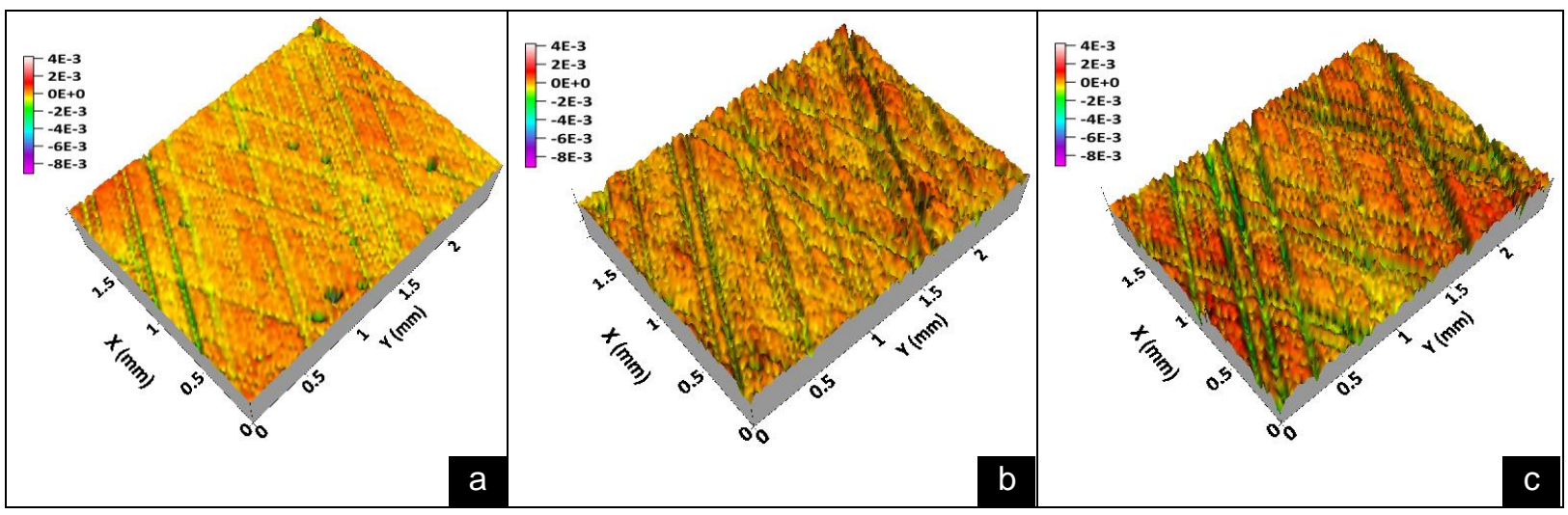

Figure 8 Three-dimensional topographies of plateau-honed surfaces produced using three different expansion velocities in the finish honing stage: (a) $1.5 \mu \mathrm{m} / \mathrm{s}$, (b) $4 \mu \mathrm{m} / \mathrm{s}$, and (c) 8 $\mu \mathrm{m} / \mathrm{s}$. (Process working variables: Abrasive grit size in the finish honing stage equal to 110 $\mu \mathrm{m}$; all other parameters are kept constant and are given in Table 1).

\subsection{Relationship between liner surface friction performance and honing process} efficiency

The specific energy is used as a fundamental parameter for characterizing the honing process. It is defined as the energy expended per unit volume of material removed. The specific honing energy defines the mechanisms of removal of material from the operated workpiece. It is calculated from the following relationships:

$$
E s p=\frac{P m^{*} t_{\text {honing }}}{Q w}
$$

where $t_{\text {honing }}$ is the effective honing time, $P m$ is the average power absorbed by the honing process, calculated as the difference between on-load power recorded during the finishing and average off-load power recorded before and after the test, and $Q w$ is the volumetric removal given by the following equation:

$$
Q w=\pi H_{c} \quad D^{2}-d^{2}
$$

where $H_{c}$ is the cylinder height, and $\mathrm{D}$ and $\mathrm{d}$ are the cylinder diameter before and after the finish honing operation, respectively.

Figure 9, which presents a plot of the friction coefficient versus specific energy, highlights the link between honing process operating conditions and the functional behavior of plateau-honed surfaces in the hydrodynamic lubrication regime. 


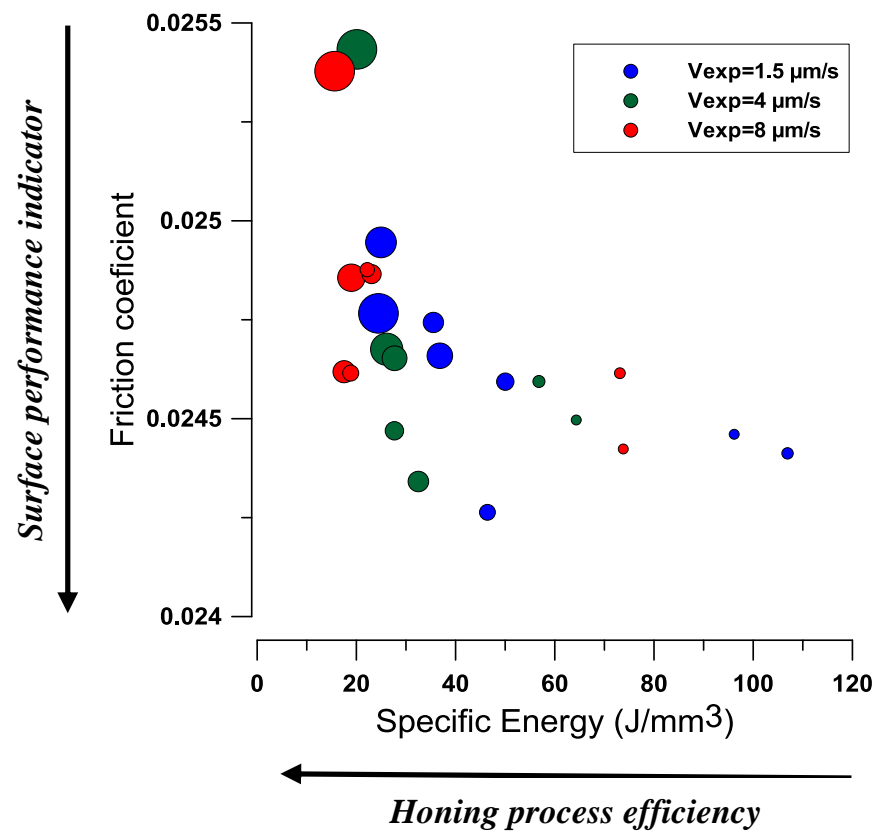

Figure 9 Predicted coefficient of friction of surface texture generated with different honing grit sizes and indentation pulse as a function of consumed specific energy during finish honing. (The size of circles is proportional to the size of the honing abrasives which varies from $30 \mu \mathrm{m}$ to $180 \mu \mathrm{m}$.)

It suggests that the optimum coefficient of friction with a good honing efficiency is reached by using a grit size of $80-100 \mu \mathrm{m}$ and an expansion velocity equal to $4 \mu \mathrm{m} / \mathrm{s}$. Furthermore, significant smooth surfaces are produced by plateau-honing with fine abrasive grit sizes due to the low indentation capacity of the fine abrasive grain. This generated surface texture also yields a low predicted coefficient of friction in the piston-ring-liner interface. However, the use of fine abrasives has the lowest efficiency. In fact, it presents lower material removal and consumes a large specific energy due to the predominance of the plowing abrasion mechanism $[9,10]$. This yields a lower stone life and generates undue tool wear. Thus, to ameliorate the honing efficiency, conventional abrasives can be replaced by superabrasive crystals which do not wear or break rapidly.

\subsection{Roughness characteristics of optimal plateau-honed surface texture}

To give a rough estimate of the potential side effects of the surface optimization, surface roughness has been evaluated using the functional roughness parameters $R_{k}$ (height of the roughness core profile), $R_{\mathrm{pk}}$ (reduced peak height), and $\mathrm{R}_{\mathrm{vk}}$ (reduced valley height) given by the ISO 13565-2 standard [9, 12]. These parameters are obtained based on the analysis of a bearing curve (the Abott-Firestone curve), which is simply a plot of the cumulative probability distribution of surface roughness height [9]. The peak height is an estimate of the 
typical height, which will likely wear down over the life of the surface. The valley height is an estimate of the typical depth of valley available to retain lubricant.

Figures 10, 11, and 12 display, for different abrasive grit sizes and at various expansion velocities, the existing correlation between the predicted friction coefficient within the cylinder ring-pack system and the functional roughness parameters of the plateau-honed surfaces of the cylinder bore, $\mathrm{R}_{\mathrm{pk}}, \mathrm{R}_{\mathrm{k}}$, and $\mathrm{R}_{\mathrm{vk}}$, respectively.

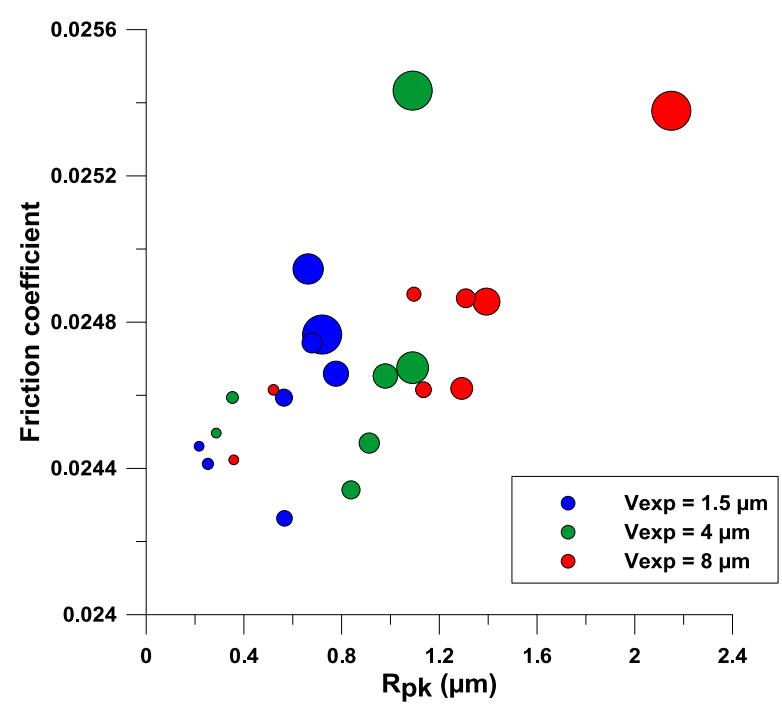

Figure 10 Predicted coefficient of friction vs. functional roughness parameter $R_{p k}$. (The size of circles is proportional to the size of the honing abrasives which varies from $30 \mu \mathrm{m}$ to 180 $\mu \mathrm{m}$.

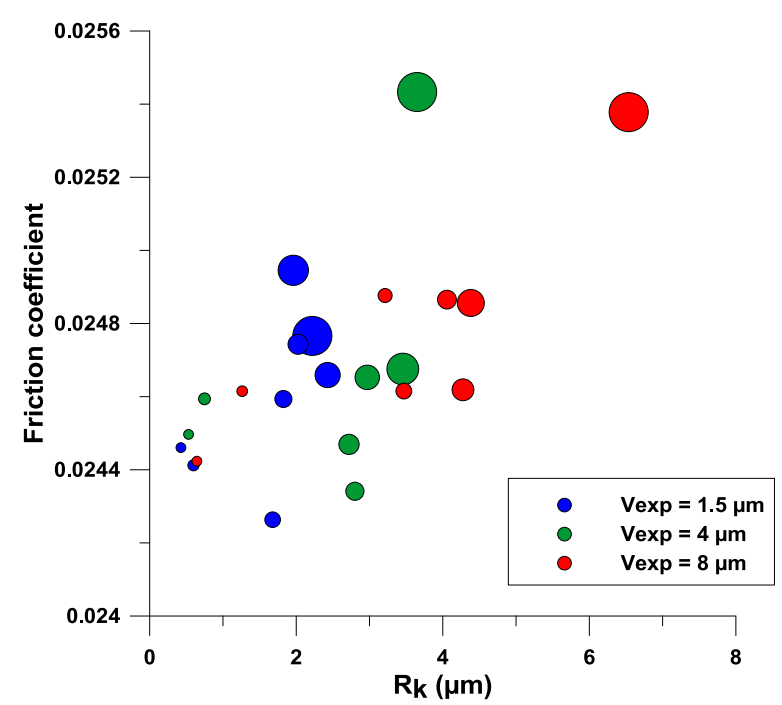

Figure 11 Predicted coefficient of friction vs. functional roughness parameter $R_{k}$. (The size of circles is proportional to the size of the honing abrasives which varies from $30 \mu \mathrm{m}$ to 180 $\mu \mathrm{m}$. 


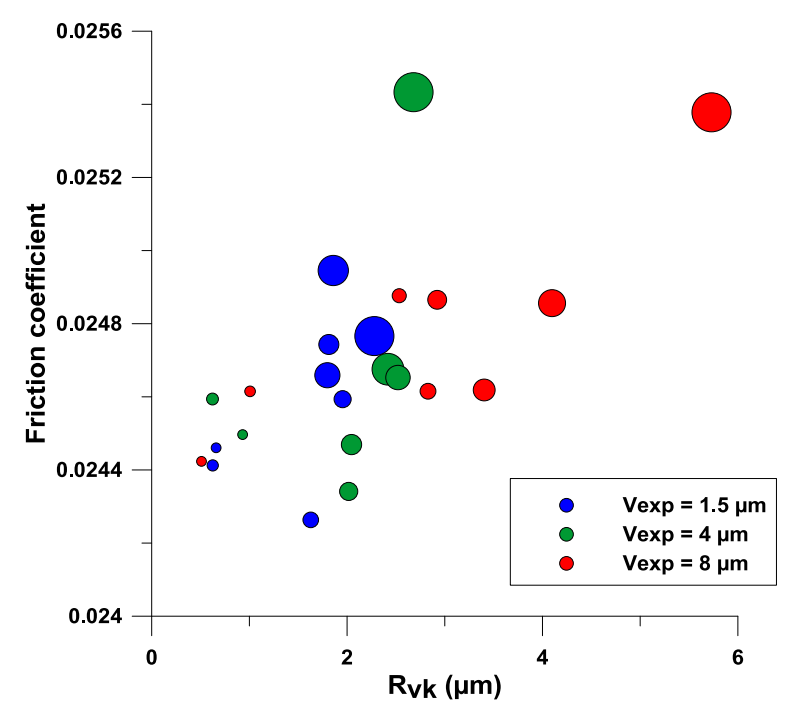

Figure 12 Predicted coefficient of friction vs. functional roughness parameter $\mathrm{R}_{\mathrm{vk}}$. (The size of circles is proportional to the size of the honing abrasives which varies from $30 \mu \mathrm{m}$ to 180 $\mu \mathrm{m}$.

These bubble plots show that all optimal surfaces in the hydrodynamic lubrication regime belong to the domain defined by:

- $\mathrm{R}_{\mathrm{pk}}<1 \mu \mathrm{m}$

- $\mathrm{R}_{\mathrm{k}}<3 \mu \mathrm{m}$

- $\mathrm{R}_{\mathrm{vk}}<2.5 \mu \mathrm{m}$

However, this critical domain does not guarantee the optimal behavior of the honed surface finish. For example, in Figure 12, the criterion $\mathrm{R}_{\mathrm{vk}}<2.5 \mu \mathrm{m}$ cannot exclude honed surfaces that induce a high friction coefficient. For the $R_{p k}$ and $R_{k}$ criteria, the same observation can be expressed. This suggests that the standard functional roughness parameters commonly used in the automotive industry cannot give a good classification of plateau-honed surfaces according to their functional performance. Table 5 shows linear correlation coefficients between roughness parameters and predicted coefficients of friction.

Table 5 The linear correlation coefficient between roughness parameters and the coefficient of friction

\begin{tabular}{|l|l|}
\hline Correlation coefficient between Rpk and $\mu$ & 0.666 \\
\hline Correlation coefficient between Rk and $\mu$ & 0.664 \\
\hline Correlation coefficient between Rvk and $\mu$ & 0.658 \\
\hline
\end{tabular}


Hence, these standard functional parameters are not sufficient to give a precise and complete functional description of "ideal" honed surfaces. This can be attributed to the fact that bearing curve analysis is one-dimensional and provides no information about the spatial characteristics and scale of surface roughness.

\section{Conclusion}

This work focused on developing ring-pack friction reduction strategies within the limitations of current production honing processes. First, three-dimensional honed surface topographies were generated under different operating conditions using an instrumented industrial honing machine. Then, the three-dimensional surface topography of each honed cylinder bore is input into a numerical model which allows the friction performance of a cylinder ring-pack system in an EHL regime to be predicted. The strategy developed allows manufacturing to be related to the functional performance of cylinder bores through characterization. The results show that an increase in grit size will lead to an increase in surface roughness, with deeper valleys leading to an increase in hydrodynamic friction. They also show that the standard functional surface roughness parameters which are commonly used in the automotive industries do not provide a link between the honing process and the generated surface performance in the hydrodynamic regime.

Note that the analysis presented in this study does not take into consideration the effects of cylinder surface topography on its ability to maintain oil, that is, the oil consumption level. Experimental studies using a reciprocating bench tester will be carried out to evaluate the effect of honing operating conditions and cylinder surface topography on scuffing and oil consumption.

\section{References}

[1] Caciu C, Decenciere E, Jeulin D. Parametric textured surfaces for friction reduction in combustion engine. Tribol Trans 2008;51:533-41.

[2] Tomanik E. Friction and wear bench tests of different engine liner surface finishes. Tribol Int 2008; 41(11):1032-38.

[3] Pawlus P. A study on the functional properties of honed cylinders surface during runningin. Wear 1994;176:247-54. 
[4] Mcgeehan J.A. A literature review of the effects of piston and ring friction and lubricating oil viscosity and fuel economy. SAE Paper, 780673; June 1978.

[5] Srivastava DK, Agarwal AK, Kumar J. Effect of liner surface properties on wear and friction in a non-firing engine simulator. Materials \& Design 2007; 28(5):1632-40.

[6] Whitehouse DJ. Surfaces - a link between manufacture and function. Proc Inst Mech Eng 1978;192:179-88.

[7] De Chiffre L, Lonardo I, Trumpold H, Lucca DA, Goch G, Brown CA, et al. Quantitative Characterisation of Surface Texture. CIRP 2000;49(2):635-52.

[8] Lemke H. Characteristic parameters of the abbot curve. MTZ 5/2003;64:438-44.

[9] Sabri L, Mezghani S, El Mansori M, Zahouani H. Multiscale study of finish-honing process in mass production of cylinder liner. Wear 2011;271:509-13.

[10] Sabri L, Mezghani S, El Mansori. Functional optimisation of production by honing engine cylinder liner. Mécanique et industrie 2010;11(5):365-77. DOI: $10.1051 / \mathrm{meca} / 2010064$.

[11] Pawlus P. Effects of honed cylinder surface topography on the wear of piston-piston ring-cylinder assemblies under artistically increased dustiness conditions. Tribol Int 1993; 26(1):49-55. DOI: 0301-679X/93/010049-07.

[12] Jocsak J, Wong V, Tian T. The effects of cylinder liner finish on piston ring-pack friction. ASME-ICED Fall Technical Conf Proc, ASME Paper ICEF 2004-952; 2004.

[13] Ehret P, Dowson D, Taylor C. On the lubricant transport condition in elastohydrodynamic conjunctions. Proc R Soc Lond, A 1998;454:763-87.

[14] Greenwood JA. Two-dimensional flow of a non-Newtonian lubricant. Proc Inst Mech Eng Part J 2000;214:29-41.

[15] Dowson D, Higginson GR. Elastohydrodynamic lubrication. The fundamentals of roller and gear lubrication. Oxford: Pergamon; 1966.

[16] Roelands CJA. Correlational aspects of the viscosity-temperature-pressure relationships of lubricant oil. PhD Thesis, Technische Hogeschol Delft, Nederlands; 1966.

[17] Habchi W, Eyheremendy D, Vergne P, Morales-Espejel G. A full-system approach of the elastohydrodynamic line/point contact problem. J Tribol 2008;130:021501 (10p).

[18] Habchi W. A full-system approach to elastohydrodynamic lubrication problems: application to ultra-low-viscosity fluids. PhD Thesis, INSA de Lyon, France; 2008.

[19] Wu SR. A penalty formulation and numerical approximation of the Reynolds-Hertz problem of elastohydrodynamic lubrication. Int J Eng Sci 1986;24:1001-13. 
[20] Venner, CH, Lubrecht, AA. Multilevel Methods in Lubrication, Tribology Series Vol. 37, Elsevier, Amsterdam, 2000. 